Koninklijke Vereniging voor Nederlandse Muziekgeschiedenis

Is Philips van Marnix de Dichter van het Wilhelmus?

Author(s): J. W. Enschedé

Source: Tijdschrift der Vereeniging voor Noord-Nederlands Muziekgeschiedenis, Deel 7, 1ste Stuk (1901), pp. 22-36

Published by: Koninklijke Vereniging voor Nederlandse Muziekgeschiedenis

Stable URL: http://www.jstor.org/stable/947658

Accessed: $21 / 06 / 2014$ 22:47

Your use of the JSTOR archive indicates your acceptance of the Terms \& Conditions of Use, available at http://www.jstor.org/page/info/about/policies/terms.jsp

JSTOR is a not-for-profit service that helps scholars, researchers, and students discover, use, and build upon a wide range of content in a trusted digital archive. We use information technology and tools to increase productivity and facilitate new forms of scholarship. For more information about JSTOR, please contact support@jstor.org. 


\section{IS PHILIPS VAN MARNIX DE DICHTER}

\section{VAN HET WILHELMUS?}

Tot de vragen, waarop het historisch onderzoek nog geen afdoend antwoord heeft kunnen geven behoort ook deze: "wie is de dichter van het Wilhelmus"? Over het algemeen wordt Marnix er voor gehouden, hoewel beslissende bewijzen daartoe niet te berde gebracht zijn. Zoo was het dus mogelijk, dat in 1896 Dr. TJaLma als stelling achter zijn proefschrift over PhiLips van MaRnix drukte: „MaRnix is de dichter van het Wilhelmus".

Destijds vernam ik bij geruchte, dat Fruiv geopponeerd had en sedert heeft zich dit bevestigd. In 1900 verscheen een geschrift over Het Wilhelmus door Postmus en daarin is afgedrukt een brief, door Fruin aan dien auteur gericht, waarin hij o. m. schrijft ${ }^{1}$ ):

„Het Wilhelmus is door een ons onbekend persoon - zeker niet MARnix en niet Coornhert - omstreeks het einde van 1568 gedicht. De auteur gevoelde innig met den Prins van Oranje mede en wist dat gevoel kunsteloos, maar aangrijpend onder woorden te brengen."

Hoewel Fruin geen gronden voor zijn meening noemt, zullen zij wel geweest zijn, dat de Wilhelmus-woorden noodwendig gedicht moeten zijn door iemand uit 's Prinsen onmiddellijke omgeving, in het einde van 1568 of het begin van 1569 en dat Marnix zich eerst in 1572 na zijn ballingschap in dienst van Willem I begaf.

Het vaderschap van Marnix berust vooral op een mededeeling van den Nijmeegschen rector VERHEIDEN, die in zijn Praestantium aliquot theologorum effigies, in 1602 verschenen, schreef ${ }^{2}$ ):

1) Blz. 101.

$\left.{ }^{2}\right)$ P. 145. Ik citeer alleen dien zin, waar het om te doen is. Letterlijk overgedrukt in М. АDАM, Vitae germanorum jureconsultorum et politicorum. Haidelbergae 1620. Vol. I p. 336. Deze auteur, somtijds aangehaald als een getuige, kan als naschrijver dus geen gewicht in de schaal leggen. 
„Ab hoc Viro etiam profecta dicitur decantata illa Cantilena composita in laudem Principis Gvilielmi Nassavii, Ad Belgas Tyrannide Albani oppressos edita."

In het volgend jaar verscheen van dit boek een vertaling door Pauwels de Kempenaer. Bij hem luidt deze passage ${ }^{1}$ ):

„Men acht oock dat van desen man, dat Liedeken eertijts gesongen ter eeren van den Prince Guilielmus van Nassouwen, sy ghemaeckt ende uytghegeven, als den Hertoge van Alba de Nederlande was onderdruckende."

Dat deze vertaling slordig is, blijkt aanstonds. De beteekenis van decantata in het midden latende is het duidelijk dat er staat:

Ook zegt men, dat van hem (MARNIX) uitgegaan is het decantata lied, dat [vroeger $\left.{ }^{2}\right)$ ] gemaakt was ter eere van Prins Willem van Nassau, toen de Nederlanders verdrukt werden door Alva's tyrannie.

Dat met dit lied het Wilhelmus bedoeld wordt, meen ik met anderen te moeten gelooven. Maar wat beteekent "decantata"? Het werkwoord decantare heeft verschillende beteekenissen gehad: recitare en valde cantare volgens DucANGE, o.a. chanter ca et la, chanter par vers, loven volgens CALEPInus, die een ietwat latere latiniteit behandelt.

De beteekenis van herhaaldelijk zingen meen ik, dat hier niet van toepassing kan zijn, omdat geen enkel voorbeeld bekend is van een Wilhelmusgebruik in de zestiende eeuw - wel van stemaanwijzing bij andere liederen, wat hier niet in aanmerking kan komen - hetgeen een beletsel is aan een ruime verspreiding te gelooven.

Met loven komt men evenınin verder, omdat de bijzin (composita enz.) reeds voldoende uitdrukt, dat het Wilhelmus een loflied is en het niet aan te nemen is, dat VERHEIDEN tweemaal hetzelfde gezegd zou hebben.

Een andere beteekenis schijnt mij nog mogelijk. Het huidige Fransche déchanter, etymologisch hetzelfde als decantare, is gelijk aan changer

1) Ik citeer volgens Schotel, Gedachten over het oude volkslied Wilhelmus. Leyd. 1834 blz. 14.

2) Ofschoon dit woord in den tekst geen equivalent vindt, meen ik echter met DE KrMpenari het te moeten opnemen; de zinsbouw schijnt mij er op te wijzen, dat dit inderdaad in de bedoeling van VERHEIDEN lag. 
de ton, welke beteekenis er blijkens den lexicograaf RicheLEt omstreeks 1700 ook reeds aangegeven werd, terwijl het Fransche décantation, volgens LITrRé, is een "opération par laquelle, après avoir laissé déposer une liqueur, on la verse doucement en penchant la vase." Ook die beteekenis is geen nieuwe; althans in 1731 vind ik vermeld het latijnsche decantatio als een scheikundige term met den zin van afgieting $\left.{ }^{1}\right)$. Zoowel het déchanter als het decantare wijzen op een verandering, op een overbrenging. Is het daarom dus onmogelijk, dat met het decantata van Verheiden ook iets dergelijks bedoeld kan zijn? Geheel onwaarschijnlijk acht ik het niet, en ik meen het woord dan zoo te moeten verstaan, dat het lied is af-, is overgegoten, van toon is veranderd, is nagezongen, vertaald is.

VERHEIDEN kan wellicht dus bedoeld hebben, dat naar het zeggen het bekend loflied op Prins Willem door Marnix vertaald is.

De tweede getuigenis, die voor Marnix te berde gebracht wordt, is de Mechelsche rederijker DE GoRTTER, die onder zijn afschrift van het Wilhelmus schreef:

$$
\begin{gathered}
\text { D'eynde } \\
1568 \\
\text { Ghecomponeert ende } \\
\text { Ghemaeckt door ionck- } \\
\text { heer philips van } \\
\text { marnicx heere } \\
\text { van sinte aldegonde } \\
\text { excellent poeet. }
\end{gathered}
$$

Volgt daaruit, dat naar zijn oordeel Marnix het Wilhelmus dichtte in 1568 ? Wanneer hij geschreven had

$$
\text { D'eynde }
$$

Ghecomponeert ende

Ghemaeckt enz.

\section{8}

ongetwijfeld; nu hij het jaartal echter bovenaan plaatste kan men er met eenigen goeden wil ook uit lezen, dat het lied in dat jaar ontstond,

1) L. M.EYEn, Woordenschat 9e dr. Amst. 1731 blz. 320. 
maar dat de redactie, die hij afschreef aan MARNIx' pen te danken is en dus later vervaardigd moet zijn.

Eén en ander wint in waarschijnlijkheid door de Fransche Wilhelmustekst van Fourmennois, die in 1895 ondekt is ${ }^{1}$ ). Daar toch luidt het opschrift: Selon le translateur Flameng", volgens den Dietschen vertaler. Nu kunnen deze woorden tweeledig opgevat worden. De mogelijkheid bestaat, dat Fourmennois het Dietsch niet voldoende machtig, door een Flamand het Wilhelmus uit het Dietsch in het Fransch heeft laten overbrengen en dezen Franschen tekst op eigen naam gepubliceerd heeft. Meer voor de hand ligt echter de andere uitlegging. Fourmennors deelt dan mede, dat zijn voorbeeld, d. i. het Dietsche Wilhelmus reeds vertaald was. Welke zijn voorbeeld was is duidelijk door de bijkans letterlijke overeenkomst van zijn Guillelmus en het Wilhelmus.

Deze laatste uitlegging geeft dus grooten steun aan de interpretatie, gegeven aan het decantata van Verheiden, terwijl ook omgekeerd deze weer gegevens aan de hand doet om Fourmennors' zeggen gemakkelijk te verklaren. Bij geen andere verklaring der teksten komen deze elkaar zoo zeer te hulp en ik meen daarom, ze met elkander vergelijkende, tot het besluit te mogen komen, dat zij ons leer $n$, dat het Wilhelmus vertaald is, en wel door Marnix.

Het Wilhelmus is dus niet ontworpen, maar vertaald door MARnix. Wanneer? lk stel in de eerste helft van 1572, al heel spoedig, nadat hij zich in 's Prinsen dienst heeft begeven. De doorgaans nauwkeurige en welingelichte WagenaAR zegt, dat het omslaan der Hollandsche steden in 1572 de aanleiding was tot het dichten van het lied ${ }^{2}$ ); Brand, die op gezag van een mondelinge mededeeling van Hugo de Groot, die zijnerzijds zich beriep op een dagregister van UITENBOGAERT, te onrechte Coornhert voor den dichter hield, noemt ongeveer hetzelfde jaar; en VALERIUS, welke aanmerkingen ook gemaakt worden op zijn Wilhelmusteksten, heeft het lied opgenomen ter plaatse, waar hij spreekt van het verschijnen van Oranje met zijn leger voor Bergen in Henegouwen

1) Ik drukte deze vertaling in haar geheel af in Bulletin des Églises urallonnes tom. VII (1899) p. 354, naar de Bibliothera belgica F 33.

$\left.{ }^{2}\right)$ Wagenar, Amsterdam in zijne opkomst. Amst. 1767 3e st. bla. 201 
in 1572. Allen noemen 1572. Deze eenstemmigheid in het noemen van hetzelfde jaar geeft te denken.

Vooral aan VALERIUs' getuigenis moet waarde gehecht worden, als oudste bericht en omdat het afkomslig is van een Zeeuw. Van FourmenNoIs toch wordt gezegd, dat hij zich in 's Prinsen leger bevond, dat van 1572 tot 1574 voor Middelburg lag, waar hij kennis gemaakt kan hebben met het lied; leden van het geslacht Fourmennors worden in het begin der zeventiende eeuw uitsluitend aangetroffen te Middelburg ${ }^{1}$ ); in $1578^{2}$ ) wordt Marnix eigenaar van de heerlijkheid Aldegonde op Walcheren, terwijl het juist Valerius, een magistraat van Veere, dus een bewoner van het eiland Walcheren is, die zich met zooveel lof uitlaat over de moreele uitwerking van het lied. Er is dus wel reden om aan te nemen, dat op zijn vroegst eerst sedert 1572 van Walcheren uit het Wilhelmus zich verspreid heeft over ons land, te meer, omdat het oudst bekende lied dat op de Wilhelmus-melodie gezongen wordt, het Ras seventien provincen ontstond kort na de overgang van Vlissingen in April 1572. Het valt op te merken, dat ook dit lied, een klare en krachtige weerklank op het Wilhelmus naar het oordeel van VAN Toorenenbergen, met de grootste waarschijnlijkheid eveneens aan MarnIX wordt toegeschreven. Uit één en ander blijkt dus, dat de oudste geschiedenis van het Nederlandsche Wilhelmus geheel voorvalt op Walcheren.

Die tijdrekenkundige aanwijzingen van Valerius, Brandt en WagENaAR werden immer als onnauwkeurige berichten ter zijde geschoven, omdat de inhoud van het lied maar al te duidelijk wijst op de jaren 1568 of 1569. Trouwens de aanteekening in de Geuzenliedboeken brengt het

1) In 1618 huwt een Catherina Fourmennols met Pieter Boudann Courten, kiesheer te Middelburg en bewindhebber van de Oost Indische Compagnie. Haar broeder Jonkheer Goaitenus Fodrmennois koopt in 1631 de heerlijkheid Popkensburg. (Smaldegange, Nieuwe cronyk van Zeeland, Middelb. 1696, blz. 484 en 669).

$\left.{ }^{2}\right)$ Hij kan er eerst in 1573 gekomen zijn, omdat hij zich toen eerst aan de zaak tegen Spanje gewijd heeft. In de opdracht 1. d. "Mars 22. An. 1601" aan „Messeignevrs dv Conseil d'Estat des Provinces unies des Pais-bas" van zijn Harangve descripte av livre dore'de Marc Avrele emperevr, ... novvellement mis en vers. A Vtrecht, par Salomon de Roy.1601 (Knuttel nr. 1169) schrijft hij pag. 5: „entre les fideles services, que jay faict, Dieu mercy, depuis XXVI 1 j. ans continuels, tant en la profession des armes, que par toute autre voye à moy possible, pour la service de Dieu, vos Sries, \& la patrie." Op blz. 8 wordt hij genoemd Capitaine. 
Wilhelmus wel in verband met die jaren, maar zegt bij nauwkeurig lezen niet, dat het lied, zooals deze verzameling het roededeelt, ook in die jaren gedicht moet zijn. Een vertaling in 1572 heft deze chronologische moeielijkheid op.

$\mathrm{Zij}$ verklaart daarbij meer. Bestond het Wilhelmus vóór 1572 niet in het Dietsch, dan kan het vóor dat jaar in de Noordelijke Nederlanden niet bekend geweest zijn als volkszang; de taal was een beletsel voor de verspreiding. Het verdient dan ook de aandacht, dat Geuzenliedboeken, bijkans ') de eenige bron, die inlichting kan geven omtrent het Wilhelmus-gebruik vóór circa 1600, alleen liederen kent op de wijze van het Wilhelmus gezongen, die gebeurtenissen na Juli 1572 behandelen.

De beantwoording der vraag, welke Marnix' voorbeeld geweest zou kunnen zijn, is moeielijk. De eerste gedachten richten zich naar Frankrijk. Het Fransch toch was Prins Willem gemeenzaam, zoo zeer zelfs, dat de woorden, die hij stervende gesproken moet hebben, Fransche woorden waren. De Wilhelmus-melodie komt uit Frankrijk en is waarschijnlijk naar 's Prinsen omgeving overgebracht in 1568 door huurtroepen, die uit Frankrijk kwamen ${ }^{2}$ ).

Een bezwaar om tot een origineel Fransch voorbeeld te besluiten blijft, althans voorshands, het feit, dat de eenig bekende Fransche Wilhelmus-tekst, die van Fourmennors, uit het Dietsche gedicht vertaald is, zooals uit het opschrift blijkt en dus niet voor het origineel gehouden mag worden.

Er staat echter meer in dat opschrift: ${ }_{\text {Et }}$ se chante sur la mesme vois. A sçauoir de Chartre". Marnix' Wilhelmus, dat volgens de Geuzenliedboeken gezongen werd op de Chartres wijs en Fourmennors'

1) „Bijkans". Bebalve het straks te citeeren lied op het beleg van Steenwijk is mij bovendien nog slechts één $16^{\mathrm{e}}$ eeuwsch lied op de Wilhelmus-melodie bekend : Een liedeken, dancseggende ende biddende voor den staedt der landen, ende den eddelen heerre Maurits van Nassau, wiens naem gemaect wert van de eerste letteren van elc vaersse. Op de voysse "Wilhelmus van Nassauwen", ofte "Rijc Godt, wien zal ic claegen, dat heymelic leyden", das es den 67en uutterssen Psalm, ofte "Mijn geest heeft my bedwongen", dat es den 29en uuttersen Psalm van LAURENB ReAal, gedagteekend 1592, afgedrukt door Dr. BREEN in Bijdragen voor vallerlandsche geschiedenis en oudhcidkunde $3 \mathrm{e}$ rks. dl. X 1 (1899) blz. 113.

$\left.{ }^{2}\right)$ Oud-Holland 1894 blz. 173. 
Guillelmus hebben dus dezelfde melodie. Uit Fourmennors' uitdrukkelijk zeggen nu, dat ze dezelfde melodie hebben, zou kunnen volgen, dat er destijds een ander Wilhelmus bestond, dat op een andere melodie gezongen werd. $\mathrm{Nu}$ is het uit de studies van VAN DuYse en van Loman bekend, dat de oorspronkelijke Chartres-melodie, zooals die ons bekend is uit een redactie van 1619 , onder den invloed der Nederlandsche enjambeerende versregels in elke strophe ingekort werd, waardoor de aanpassing van den Wilhelmus-tekst aan die Fransche melodie, althans in het tweede gedeelte, vrijwel onmogelijk is. Is het niet opmerkelijk dat, hoewel de Wilhelmus-woorden en de Chartres-wijs historisch buiten kijf bij elkaar behooren, de oudste vaststaande Wilhelmus-volksmelodie, die van 1607 , betrekkelijk weinig overeenkomst met de Chartres-voois vertoont en dat op die zoo zeer gewijzigde melodie van 1607 de Wilhelmus- en ook de Guillelmus-woorden zich uiterst gemakkelijk laten scandeeren? Het is niet wel aan te nemen, dat iemand als MARnIx een lied zou gemaakt hebben, dat zich zoo slecht zou voegen naar die melodie van 1619; MarnIx' melodie kan, in verband met Fourmennols' opschrift, wellicht dus alreeds een gewijzigde Chartres-melodie geweest zijn.

Wanneer nu in dit verband Valerius' noteering van het Wilhelmus geraadpleegd wordt, dan verschijnt deze in een nieuw licht. Weliswaar is deze noteering niet in logische verbinding te brengen met de andere bekende teksten uit de $17 \mathrm{e}$ eeuw, in aanmerking genomen, dat VALERIUS, of wie hem in het muzikale gedeelte van zijn arbeid ter zijde gestaan heeft, uit zijn geheugen een melodie citeerde, zooals die vroeger gehoord was, terwijl zij in den tijd, dat hij (VALERIUs) haar neerschreef, zich principiecl vervormd had, is het dus niet onmogelijk, dat daarbij wel is waar grove fouten begaan werden, maar dat die noteering toch wel degelijk een kern van waarheid, maar ook niet meer dan dat, bevat. Die kern zou dan reeds afwijkend zijn van de Chartresmelodie, een eigendommelijk nationaal karakter vertoonen en in de Gedenck-clank terecht opgenomen zijn onder de Nederlandsche stemmen ${ }^{1}$ ), wat tot heden raadselachtig bleef.

1) Vgl. hiermede wat ik schreef in Oud-Holland $1894 \mathrm{blz} .189$. 
Uit Fourmennors' Wilhelmus-opschrift kan dus de gevolgtrekking gemaakt worden, dat in 1572 een ander te loor gegaan Fransch Wilhelmus bestond, dat gezongen werd op de nog niet gewijzigde Chartres-voois.

Iets anders is echter ook mogelijk en wel, dat die melodie van het oorspronklijk Wilhelmus een geheel andere geweest is. De aandacht valt dan op den Duitschen Wilhelmus-tekst in Das Ambraser Liederbuch van 1582, waar als stemaanwijzing gedrukt is: "Im Thon wie der Graff zu Rom".

Deze melodie, die door BöHME teruggevonden werd in een druk van 1609 , werd in 1771 aangegeven als stemaanwijzing van het overoud Grisellislied en nu is het wel opmerkelijk, dat Lootens en Feys in 1879 ditzelfde lied publiceerden met een andere melodie ${ }^{1}$ ), waarin VAN Duyse weer stellige overeenkomst ontdekte met de drie eeuwen oudere Chartres-wijs ${ }^{2}$ ).

Moet op grond hiervan een Duitsch Wilhelmus als MARNIx' voorbeeld aangezien worden? De bekende Duitsche Wilhelmus-teksten kunnen niet in aanmerking komen, omdat zij blijkbaar vertalingen uit het Dietsch zijn. De wisselwerking der verschillende melodieën op elkander, die bij ontstentenis van de noodige gegevens, zich beter doet gevoelen dan beschrijven, maakt een vaste overtuiging in deze hoogst moeielijk, zoo al niet onmogelijk.

Als slotsom meen ik echter te mogen schrijven:

1. De gronden, waarop men MaRnix houdt voor den ontwerper van het Wilhelmus, zijn geheel onvoldoende.

2. Wel daarentegen heeft hij aan het lied zijn huidigen vorm gegeven in 1572, door vertaling van een bestaand lied.

3. Dat destijds reeds bestaand lied is gedicht in 1568 , waarschijnlijk in het Fransch, wellicht op de Chartres.wijs.

Zooals boven gezegd is, kan met goede grond aangenomen worden, dat het Wilhelmus, gezongen op een gewijzigde Chartres-melodie, in 1572 van Walcheren uit zijn intree in de Noordelijke Nederlanden gedaan heeft.

1) Zie Vas Durss, Het oude Nederlandsche lied. 's-Grarenh. 1901 blz. 270, 271.

2) Tijdschrift dl. V blz, 177 . 
Slechts langzaam heeft het zich daar vasten voet verworven, terwijl het zich in de Zuidelijke Nederlanden niet zou weten staande te houden. In 1569 dient zij nog voor een ander Fransch historie-lied ${ }^{1}$ ); een paar maal geeft Fourmennors als wijsaanduiding zijner historie-liederen op het beleg van Doornik (1581) "sur la vois de Chartres" en kent $L a$ pievse alovette van 1619 de melodie, maar daarmede zijn dan ook de de eenig bekende plaatsen aangehaald, die wijzen op een bekendheid der melodie in de Walsche districten.

Voor de Noordelijke Nederlanden blijkt het bestaan van het lied vóór $1580 \mathrm{mij}$ alleen uit het Geuzenliedboek. In het noordelijk deel van het land was de melodie naar het schijnt toen nog niet doorgedrongen. Het lied toch Vande heerlijcke triumphe over 't vertrec der W'alen uit Groeningen $\left(1576^{2}\right)$, geeft als stemaanduiding ${ }_{n}$ na de wyse van den Grave van Romen", dezelfde melodie dus, waarop het Wilhelmus in Duitschland gezongen werd. Zulks wijst, in verband en samenhang beschouwd, er vrij wel op, dat de Wilhelmus-wijs destijds in Groningen niet bekend, althans niet populair was.

Zestien jaar later was zij het daarentegen wel in de noordelijke contreien en zoo er eenige twijfel nog mocht bestaan of de melodie van $O$ la folle entreprise inderdaad wel geïdentificeerd mag worden worden met de "wyse van Chartres", is het volgende lied op het beleg van Steenwijk in 1592 wel het beste middel dien twijfel weg te nemen. Het eerste couplet toch is een omwerking van het Chartres-lied - ter vergelijking volge hier nog eens de eerste strophe -

0 la folle entreprise

Du prince de Condé!

A Chartres la jolie

Il a voulu entrer;

C'est à luy grand folie,

Il n'y entrera pas:

Les bons soldatz de France

Ne le souffriront pas.

1) VAN DUYse in Tijdschrift dl. $\mathrm{v}$ blz. 156.

$\left.{ }^{2}\right)$ Geuzen-liedboek. Uitgave VAN LUMMeL nr. 121. 
terwijl niet de Chartres-melodie, maar wel het Wilhelmus uitdrukkelijk als melodie wordt aangegeven. Daaruit blijkt dus hoezeer de benaming der Chartres-wijs overgegaan was in die van het Wilhelmus, want, zoo ergens dan was hier zeker aanleiding te over het $O$ la folle entreprise voor te schrijven. $\mathrm{V}_{\text {AN }}$ Duyse twijfelde an die stemaanwijzing niet ${ }^{1}$ ); citeerende echter naar VAN Vuoten's Nederlandsche geschiedzangen, had hij geen absolute zekerheid, omdat $\mathrm{V}_{\text {AN }} \mathrm{V}_{\text {Loren, }}$ niet alleen slechts eenige gedeelten van het lied afdrukt, maar daarbij, zooals hij immer deed, stelselmatig de muzikale aanwijzingen verwaarloost. Ik neem uit die onvolledigheid aanleiding het geheele lied naar het origineel ${ }^{2}$ ) af te drukken:

Chanson getree hors Steenvvijc par l'ennemy y assiege l'an 1592.

Et la Responce:

Sur la voix de Guillelmus de Nassauwe. PROPOSITION. RESPONCE.

De la folle entreprise

Des Comtes de Nassan

A Steenwijc la jolie

Ils donneront l'assault

Cest tout a eux follie

Ils ny entreront pas

Les bons Soldats de Steennijc

$\mathrm{Ne}$ le souffriront pas.

Ils pensent a la foulle

Entrer en ce lieu

Et nous donner la crainte

Ne pouoir resister

Vos coups de cannōnades

Dont vous vous fiez tant

Mais Dieu par sa missance

Fera bien tourner le vent.
O la sage entreprise

Des Comtes de Nassau

Car Steenvvijc sera prise

Maulgre ce grand Papau

Qui pense la defendre

Contre ce camp Royal

Mieulx feroit de la rendre

A nostre General.

Nos chiefs \& gens de guerre

Se asseurent d'emporter

Ce lieu qui nest que terre

Ne poura resister

A tant de cannōnades

Dont on le battera

Et a tant d'escalades

Dont ont l'attacquera.

1) Tijdschrift dl. V blz. 156.

2) Achter Een historiael ghesangh enz. In 's-Gravenhage, by Aelbrecht Heyndricxz. Anno M.D.XCIIr. 
IS PHILIPS VAN MARNIX DE DICHTER VAN HET WILHELMUS?

Alles courir en France

Au secours du biernoy

Lequel est en souffrance

Par la puissance du Roy

d'Espaigne nostre bon Prince

Auquel demeurerons

Fidel en son seruice

Tant que nous viuerons.

Roan ville fidelle

Au Catholicque foy

Laquell' est deliuree

Des forces du biernoy

Par le bon Duc de Parme

Gounerneur general

Qui a acquis grand gloire

Et tous ses bons soldats.

Retires vous Angloises

Et feres sagement

Vous aussi Hollandoises

Frisons vn regiment

Alles laicter vos vaches

Et eugraisser vos boufs

Icy n'auez que faire

Vous y serez battus

Vous Hugenots rebelles

A Dieu \& vostre Roy

Seruez vne Isabelle

La Reyne des Angloys

Laquelle sera sans doubte

De brief \& en vn cop

Assailli de grands forces

Pour faire le has'op.
Craindant nostre vaillance

Ce Papau nous semond

D'aller courir en France

Secourir ceulx qui nont

Besoin de gens de guerre

Pour mettre le ligeur

Sept fois sept pieds soubs terre

S'il attent la rigeur.

Roan ville rebelle

A Dieu \& a son Roy

Se ligant infidelle

Contre la vraye foy

N'est par le Duc de Parme

Remise en tel Estat

Que le Royal gendarme

Ne layt quand Dieu vouldràt.

Nos enseignes Angloises

Feront plus sagement

Aussi nos Hollandoises

Et le grand Regiment

Du bon pays de Frise

Acoustrans ces Papaus

De Steenvvijc a la guise

De pellerins pitaux.

L'Hugenot est fidelle

A Dieu \& a son Roy

La grand Reyne Isabelle

Defend la vraye foy

Que si le Roy d'Espaigne

La presse plus avant

Il verra ce que gaigne

Qui se va ruinant. 
CONSEIL SALVTAIRE,

aulx assieges en Steenvvijc,

1592.

Soldats de la villette

De Steenvvijc, Rendes vous

Ne croyez a la teste

Qui vous abuse tous

Dieu par tout est propice

A ce que s'entreprendt

Par le Comie Mavrice

Guerrier tresexcellent.

Iadis Le Duc Maurice

Son ayeul deuant soy

Chassa Charles d'Austrice

Pere de vostre Roy

Croyes que d'vn corage

Aultant noble \& vaillant

Ce Prince preux \& sage

Luy en fera aultant.

Voire jusqu'en Espaigne

Il ira l'assaillir

De France \& d'Allemaigne

Il aura (sans faillir)

Seigneurs \& Gentilzhommes

Qui l'accompaigneront

A qui les grosses sommes

d'Argent ne mancqueront.

Mais avant qu'entre prendre

Cest exploit genereulx

Par force il fera rendre

VII.

Au parmoys cauteleux 
Ce dequoy par famine

En Flandres \& Brabant

Et par sa doulce mine

ll s'est faict conquerant.

\section{La Reyne d'Angleterre}

Nos Estats Generaulx

Et par mer \& par terre

Donneront tant d'assaulx

A vostre Roy Philippe

Qui se met en pourpoint

Et ses tresors dissipe

Pour ce qu'il naura point.

Ce Roy sans Pair de France

Qu'appelles biarnoys

Fera par sa prudence

Que tout vray bon Françoy

Luy fera compaignie

D'vn vnanime vol

Pour chasser d'Italie

Le Pape' \& l'Espaignol.

Quand a ce que de Parme

Auecq son grand arroy

A donne quelqu'allarme

Au camp de ce grand Ro

Il s'est en fin de Compte

Retire bien blesse

Avecq sa Courte bonte

Confus \& harrasse.

Soldats on vous abuse

Vous naurez nul secours

Par force ne par ruse

En six fois trente jours 


\author{
Cependant on s'appreste \\ Pour d'vn sault furieux \\ Getter vostre villette \\ Jusqu'au planchier des cieulx.
}

Fin.

Wie de dichter van deze strophen was, blijkt nergens; wellicht was het eveneens Fouranewnors. Daar de opdracht van Een historiael ghesangh aan de Staten Generaal is onderteekend: „Vr. Excion. ende Ee. ootmoedighe ende dienstvvillighe Dienaer ende Soldaet C. V. T.", achter welke initialen schuil gaat een persoon, die zich elders $\left.{ }^{1}\right)$ Trello noemt, is er aanleiding te over den vervaardiger van dit Steenwijksch lied in het leger te zoeken. Daar nu de geuzenliederen ook soldatenliederen zijn en het Wilhelmus voor zoo ver bekend in dezen tijd elders zoo goed als niet aangehaald wordt, blijkt er opnieuw uit, hoe of het lied eigenlijk alleen bekend was in het leger vóór $1600{ }^{2}$ ).

Eenigszins vreemd staat daar tegenover de bekende mededeeling van Verheiden, waaruit gelezen kan worden, dat het lied alom verspreid was. Toch is zulks te verklaren. Verheiden's boek verscheen in 1602, dat is acht jaar na zijn huwelijk, den 13 Augustus 1594 gesloten met Naeleke van Dornichs, weduwe van den kapitein (hopman) ARendt Hessels "); haar broeders WoLter en $\mathrm{J}_{\Lambda N}$ waren eveneens krijgslieden en zij zelve was herhaaldelijk bij militaire feiten geweest, o.a. in 1579 bij de inneming van Maastricht. Voldoende aanwijzingen zijn daarin om met goeden grond te kunnen vermoeden, dat VerHeiden's zegslieden zijn naaste familieleden geweest zijn. Aan zijn bericht kan dus geen verdere strekking gegeven worden dan dat in 1600 het Wilhelmus bekend was vooral, zoo niet uitsluitend, in het leger en dat men daar Marnix voor den vertaler hield.

1) Vel C. 1 recto.

$\left.{ }^{2}\right)$ Zie Oud Holland t. a. p. blz. 223.

$\left.{ }^{3}\right)$ Oorkondenboek van het geslacht Doornick of Doorninck. Haarl. 1894 nr. 525 Ik dank de kennis van dit huwelijk als ook van de andere genealogische gegevens aan den heer P. N. van Doornincik, den samensteller van het Oorliondenboek. 
Ten slotte nog enkele positieve bijdragen.

In mijn eerste Wilhelmus-opstel ${ }^{1)}$ bracht ik bij elkander, wat mij bekend was geworden omtrent het Wilhelmus-gebruik in vroegere eeuwen. Door Postmus wordt daaraan toegevoegd Haagsche straatjongens, die in 1653 op het Binnenhof het Wilhelmus bliezen op trompetjes met Oranje papier omwonden ${ }^{2}$ ). Die bijdragen worden vermesrderd met de berichten, dat den 30 November 1600 door Hollandsche trompetlers het Wilhelmus geblazen wordt op de kade te Antwerpen, toen den vorigen dag van Dordrecht uit met goed gevolg een onderneming tegen die stad op touw gezet was ${ }^{3}$ ), dat, toen Schoonhoven den 19 September 1787 in handen der Pruisen gevallen was "t beruchte liedje" Wilhelmus rondom weergalmde ${ }^{4}$ ) en dat gedurende de omwenteling en de Fransche overheersching de melodie door het klokkenspel te Arnemuiden gespceld werd ${ }^{5}$ ). Het valt op te merken, dat beide eerste berichten wederom alleen spreken van het gebruiken der melodie op de trompet, niet der woorden, en het bekend zijn daarvan in het legel en bij het gepeupel. Zij bevestigen dus de meening, dat het historisch volkomen onjuist is, het Wilhelmus te beschouwen als van ouds een volkslied in den zin van hymne national, hetgeen maar al te dikwerf geschiedt.
Haarlem,
J. W. ENSGhedÉ.

\footnotetext{
1) Oud-Holland t. a. p. blz. 220 vlg.

2) t. a. p. blz. 98 .

3) J. EXSTEN in Elsevier's Maandschrift 1900 blz. 448.

4) Von Prau, Geschiedenis van de veldtogt der Pruissen in Holland. Amst. 1792 blz. 75.

5) KEsteloo, Geschiedenis en plaatsbeschrijving van Arnemuiden. Middelb. 1875 blz. 71 .
} 